\title{
Análise da disposição afetiva do aluno em um AVEA: descoberta do desânimo
}

\author{
Fabrícia Damando Santos ${ }^{1,2}$, Magda Bercht ${ }^{1}$ \\ ${ }^{1}$ Universidade Federal do Rio Grande do Sul (UFRGS) \\ Caixa Postal 15.064 - 91.501-970 - Porto Alegre - RS - Brazil \\ ${ }^{2}$ Universidade Estadual do Rio Grande do Sul (UERGS) \\ Engenharia da Computação - Guaíba - RS - Brazil \\ fabriciadamando@gmail.com, berchteinf.ufrgs.br
}

\begin{abstract}
This paper presents a study to students' validate observable indicators used to characterize the students' mood state of the discouragement when interacting in a virtual learning environment. The results of the case study from the students' affective dispositions are reported in the paper and presented the indicator variables of discouragement.
\end{abstract}

Resumo. Este artigo apresenta uma pesquisa realizada para validar indicadores observáveis de alunos para que sejam usados para caracterizar o estado de ânimo desanimado do aluno em interação em um ambiente virtual de ensino e aprendizagem. Os resultados do estudo de caso realizado, a partir das disposições afetivas dos alunos, são relatados no trabalho bem como são destacadas as variáveis indicadoras do desânimo.

\section{Introdução}

Como uma das potencialidades dos AVEA é possibilitar que os participantes de um curso possam interagir, pois é através das interações que ocorrem possibilidades de ações/trocas mediadas pelas suas ações no ambiente ao utilizar ferramentas de comunicação (BEHAR et al, 2013, pg.47). No contexto das interações, o afeto e atributos afetivos subjacentes ao aluno se mostram presentes e podem interferir nos processos de aprendizagem, processos de atenção, memorização, raciocínio e motivação (LONGHI, BEHAR e BERCHT, 2009; DAMASIO, 1996).

Dessa forma, uma das preocupações na aprendizagem diz respeito aos aspectos afetivos que afetam negativamente a aprendizagem. Indivíduos que estão em situações de desânimo, por exemplo, se veem confrontados com situações que não conseguem ultrapassar, levando o aluno a um estado de apatia e passividade, representado, muita das vezes por afetos negativos, visto ser difícil aceitar as próprias limitações (SELIGMAN e CSIKSZENTMIHALY, 2000).

É com esse intuito que o presente estudo, busca verificar e validar variáveis observáveis que possam ser utilizadas para mapear e indicar o estado de ânimo desanimado do aluno em um AVEA a partir da análise da sua disposição afetiva. Os indicadores ou variáveis comportamentais são as ações que o aluno realiza dentro do ambiente (tempo de demora em fazer uma atividade, número de erros que comete na 
execução de uma atividade, número de solicitações de ajuda, a forma de se expressar em textos, dentre outras) (BERCHT, 2001).

Este trabalho encontra-se organizado em seções, sendo que a seção 2 aborda o referencial teórico sobre a afetividade e os estados de ânimo, cujo enfoque será o desânimo. A seção 3 apresenta a metodologia aplicada e detalha o experimento realizado, além da discussão da análise. As considerações finais encontram-se na seção 4, bem como, apresentação de trabalhos futuros.

\section{Fenômenos Afetivos}

De modo geral, o termo afetividade engloba os termos emoções, sentimentos, paixão, personalidade, motivação, estados de ânimo, entre outros (BERCHT, 2001). Para Damásio (2000) e Picard (2000) a influência da emoção vai além de como a reconhecemos e a expressamos, podendo influenciar nos processos de raciocínio de decisão. Para Scherer (2005) a afetividade diz respeito à habilidade de experimentar sentimentos e a eles reagir, o que pode incluir um conjunto de fenômenos afetivos que possuem diferentes origens, intensidade, duração e reações corporais. Dessa forma, estados de ânimo são fenômenos afetivos de baixa intensidade e longa duração, classificados em: animado ou desanimado, satisfeito ou insatisfeito, disposto ou indisposto, concentrado ou desatento (SCHERER, 2005).

\subsection{Estado de ânimo desanimado}

O desânimo surge quando há sentimento de que não há nada mais a ser feito, culminando em esgotamento (JBEILI, 2004). O autor descreve que quem vive o desânimo não aceita desafios, esquiva-se da ansiedade provocada pelas tentativas, tenta evitar repetições de fracasso, tornando a pessoa apática e indiferente, fazendo com que a mesma evite tomar decisões.

Scherer (2005) considera o desânimo como um estado de ânimo de baixo controle e valência negativa. O autor propôs a GEW (Geneva Emotion Wheel) que é um modelo possível que o usuário identifique uma emoção vivenciada via auto-relato, possibilitando verificar sentimentos relacionados ao desânimo. O modelo encontra-se na sua segunda versão GEW 2.0, desenvolvida por Sacharin, Schlegel e Scherer (2012).

Como trabalhos relacionados aplicando a GEW destaca-se a pesquisa de Santos (2008) que a aplica para obter valores de tensão do usuário através de cenas de jogos em mundos virtuais e realizando análise estatística dos resultados. No contexto educacional, encontra-se o trabalho desenvolvido por Longhi (2011) o qual apresenta uma adaptação da GEW para compor a dimensão afetiva de alunos em AVEA juntamente com traços de personalidade, porém, de difícil praticidade devido à necessidade do profissional de psicologia para tal aplicação do teste de personalidade. No presente trabalho, após a validação das variáveis, pressupõe-se que essas poderão ser utilizadas no desenvolvimento de regras de comportamento dentro do AVEA via mineração de dados para prever alunos em processo de desânimo.

No presente trabalho, a GEW 2.0 foi adaptada e chamada de REA (Roda de Estados de ânimo) 2.0, pois além de possuir as 20 famílias afetivas, possui quatro quadrantes os quais englobam os estados de ânimo representativos no processo de aprendizagem, e classificados em função das emoções: logrativas (satisfação), 
antagônicas (insatisfação), resignativas (desânimo) e as condutivas (ânimo) (LONGHI, 2011). A REA 2.0 é apresentada pela figura 1.

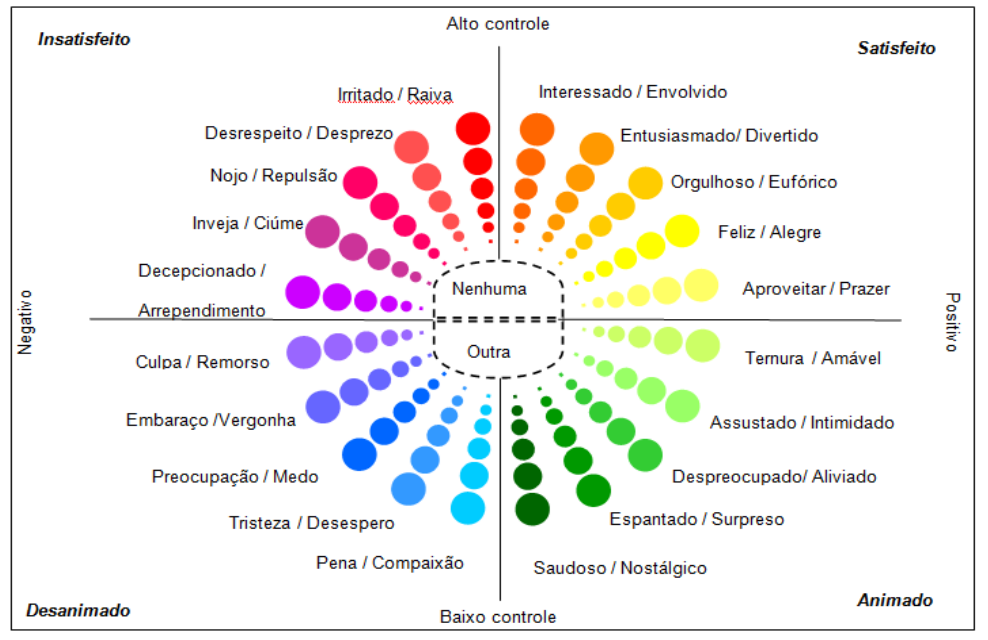

Figura 1: Roda de estados de ânimo REA 2.0

\section{Procedimentos Metodológicos}

A pesquisa desenvolvida é de natureza aplicada ao processo de ensino e aprendizagem, classificada como exploratória, utilizando estudo de caso como procedimento técnico e questionário como instrumento. A população alvo da pesquisa inclui alunos da disciplina que usam o AVEA Moodle na UFRGS para a unidade de estudo ECO 3010 Análise de Demonstrações Contábeis. A pesquisa contou com 58 alunos matriculados em 2014/1 possuindo uma amostra participante do instrumento questionário com 41 alunos. Os resultados dos questionários foram tabulados através do software SPSS.

\subsection{Análise descritiva do Estudo de Caso 2014/1}

Após a tabulação dos dados, a primeira questão que diz respeito em como o aluno se sente quando envia atividades com atraso e segunda questão como o aluno se sente quando envia atividades em grupo com atraso. $\mathrm{O}$ resultado das duas questões encontra-se ilustrado através da figura 2. Observa-se, que a maioria das respostas encontra-se no quadrante relacionado ao estado de ânimo desanimado (Pena/Compaixão, Tristeza/Desespero, Preocupação/Medo, Embaraço/Vergonha, Culpa/Remorso). Para a primeira questão, cerca de, 18 alunos relataram sentir alguma das emoções relacionadas ao estado de ânimo desanimado e, para a segunda questão a frequiência foi de 28 alunos.

Foi questionado ao aluno se ele sentia dificuldade em realizar as atividades individuais (escala Likert), também se realizou a tabulação cruzada desta questão com a questão de como o aluno de sentia ao enviar atividades em atraso (REA 2.0). $\mathrm{O}$ resultado pode ser analisado através da tabela 2. 


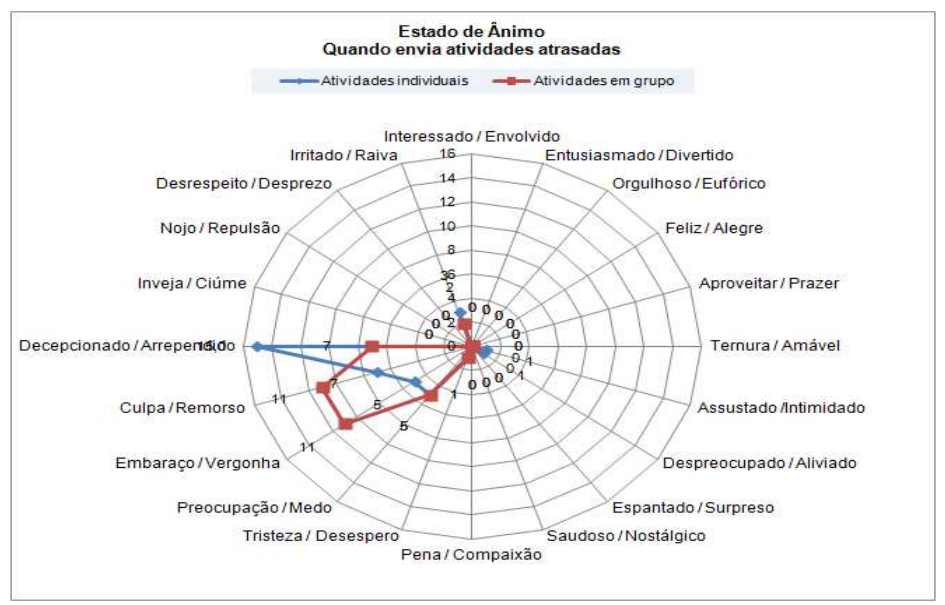

Figura 2: Estado de ânimo ao envio de atividades em atraso

Tabela 1 constando a tabulação cruzada realizada para validação das variáveis.

Tabela 1: Dificuldade em realizar atividades individuais

\begin{tabular}{|c|c|c|c|c|c|}
\hline \multirow[t]{2}{*}{$\begin{array}{l}\text { Como você se sente quando envia } \\
\text { atividades individuais em atraso? }\end{array}$} & \multicolumn{4}{|c|}{$\begin{array}{l}\text { Atividades individuais - Você sente dificuldade em } \\
\text { realizá-las? }\end{array}$} & \multirow[t]{2}{*}{ Total } \\
\hline & $\begin{array}{l}\text { Algumas } \\
\text { Vezes }\end{array}$ & Nunca & $\begin{array}{l}\text { Quase } \\
\text { Sempre }\end{array}$ & Raramente & \\
\hline Assustado /Intimidado & 1 & 0 & 0 & 0 & 1 \\
\hline Despreocupado / Aliviado & 1 & 0 & 0 & 0 & 1 \\
\hline Tristeza / Desespero & 0 & 0 & 0 & 1 & 1 \\
\hline Preocupação / Medo & 4 & 0 & 0 & 1 & 5 \\
\hline Embaraço/Vergonha & 5 & 0 & 0 & 0 & 5 \\
\hline Culpa / Remorso & 3 & 1 & 1 & 2 & 7 \\
\hline Decepcionado / Arrependido & 8 & 0 & 2 & 5 & 15 \\
\hline Irritado / Raiva & 2 & 0 & 0 & 1 & 3 \\
\hline Nenhuma & 0 & 0 & 1 & 0 & 1 \\
\hline Não respondeu & 0 & 0 & 1 & 1 & 2 \\
\hline Total & 24 & 1 & 5 & 11 & 41 \\
\hline
\end{tabular}

Através da análise dos resultados, observou-se que essas variáveis podem ser utilizadas para o mapeamento das observáveis indicadoras do desânimo. Foi feita a tabulação cruzada em como o aluno se sente ao enviar atividades individuais em atraso usando a REA 2.0 e com qual freqüência ele realmente as envia (escala Likert). A maioria dos alunos que entregam atividades em atraso também sentiu dificuldade em realizá-las e, em ambos os casos, apresentaram emoções relacionadas ao desânimo. O mesmo resultado foi encontrado quando se tratava de atividades em grupo, o que também motiva o uso dessas variáveis para o mapeamento das observáveis como indicadoras ao desânimo.

Através dessas e das demais questões tabuladas, foi possível verificar e validar as seguintes variáveis como indicadoras do desânimo: Quantidade de vezes que enviou atividades individuais em atraso; Quantos dias de atraso por atividade individual; Quantidade de vezes que enviou atividades em grupo com atraso; Quantos dias de atraso por atividade em grupo; Quantidade de tentativas para enviar material; Quantidade e tipos de solicitações de ajuda ao professor; Qual ferramenta mais solicita ajuda do professor; Auto-relato: Dificuldade em utilização de ferramentas do AVEA Moodle; 
Auto-relato: Dificuldade na realização das atividades individuais e em grupo; Autorelato: Dificuldade em acompanhar conteúdos.

\section{Considerações Finais}

O presente trabalho apresentou uma análise da disposição afetiva do aluno em um curso EAD e, a partir do estudo de caso realizado, foi possível verificar, validar e mapear variáveis observáveis que possam ser utilizadas para indicar o estado de ânimo desanimado, fornecendo indícios de quais dados devem ser selecionados no AVEA para possibilitar esta inferência. Através desses indicadores, regras comportamentais podem ser desenvolvidas para realizar a inferência do desânimo a fím de desenvolver subsídios computacionais que apóie o professor em suas práticas pedagógicas, ao identificar alunos propensos ao desânimo.

Pretende-se em trabalhos futuros, realizar a mineração de dados educacionais utilizando as variáveis comportamentais mapeadas na presente pesquisa, utilizando-as como indicadores para a inferência do desânimo, para posteriormente, fornecer subsídios computacionais ao professor, apoiando-o nessa inferência.

\section{Referências}

BEHAR, P. A. et al. (2013). Competências: Conceito, elementos e recursos de suporte, mobilização e evolução. Competências em Educação a Distância. Porto Alegre: Penso.

BERCHT, M. (2011). Em Direção a Agentes Pedagógicos com Dimensões Afetivas. Tese de doutorado. Universidade Federal do Rio Grande do Sul. Programa de PósGraduação em computação.

DAMÁSIO, A. (1996). O erro de Descartes: emoção, razão e o cérebro humano. São Paulo: Companhia das Letras.

JBEILI, C. (2004). Superando o desânimo antes que ele supere você. São Paulo: Editora Nobel.

LONGHI, M.; BEHAR, P. A.; BERCHT, M. (2009). A Busca pela Dimensão Afetiva em Ambientes Virtuais de Aprendizagem. Modelos Pedagógicos em Educação a Distância. Porto Alegre: Artmed.

PICARD. R. W. (2000). Affective Computing. The MIT Press.

SACHARIN, V.; SCHLEGEL, K.; SCHERER, K. R. (2013). Geneva Emotion Wheel Rating Study. Geneva, Switzerland: University of Geneva, Swiss Center for Affective Sciences.

SANTOS, J. M. R. (2008). Gaia: Intelligent Control of Virtual Environments. Dissertação de Mestrado. Universidade Técnica de Lisboa.

SCHERER, K.R. What are the emotions? And how can they measured? (2005). In: Social Science Information. Disponível em: http://www.affectivesciences.org/system/files/2005_Scherer_SSI.pdf

SELIGMAN, M. E. P.; CSIKSZENTMIHALYI, M. (2000). Positive Psicology: An Introduction. American Psychologist. Vol 55, pg. 5-14. Jan. 